\title{
A low-cost wireless temperature sensor: evaluation for use in environmental applications
}

Article

Published Version

Young, D. T., Chapman, L., Muller, C. L., Cai, X. M. and Grimmond, C. S. B. (2014) A low-cost wireless temperature sensor: evaluation for use in environmental applications. Journal of Atmospheric and Oceanic Technology, 31 (4). pp. 938-944. ISSN 1520-0426 doi: https://doi.org/10.1175/JTECHD-13-00217.1 Available at https://centaur.reading.ac.uk/36100/

It is advisable to refer to the publisher's version if you intend to cite from the work. See Guidance on citing.

To link to this article DOI: http://dx.doi.org/10.1175/JTECH-D-13-00217.1

Publisher: American Meteorological Society

All outputs in CentAUR are protected by Intellectual Property Rights law, including copyright law. Copyright and IPR is retained by the creators or other copyright holders. Terms and conditions for use of this material are defined in the End User Agreement.

www.reading.ac.uk/centaur 
Central Archive at the University of Reading

Reading's research outputs online 


\title{
A Low-Cost Wireless Temperature Sensor: Evaluation for Use in Environmental Monitoring Applications
}

\author{
Duick T. Young, lee Chapman, Catherine L. Muller, and Xiao-Ming Cai \\ School of Geography, Earth and Environmental Sciences, University of Birmingham, Edgbaston, Birmingham, \\ United Kingdom \\ C. S. B. GRIMMOND \\ Department of Meteorology, University of Reading, Reading, United Kingdom
}

(Manuscript received 14 October 2013, in final form 4 February 2014)

\begin{abstract}
A wide range of environmental applications would benefit from a dense network of air temperature observations. However, with limitations of costs, existing siting guidelines, and risk of damage, new methods are required to gain a high-resolution understanding of spatiotemporal patterns of temperature for agricultural and urban meteorological phenomena such as the urban heat island. With the launch of a new generation of low-cost sensors, it is possible to deploy a network to monitor air temperature at finer spatial resolutions. This study investigates the Aginova Sentinel Micro (ASM) sensor with a custom radiation shield (together less than USD\$150) that can provide secure near-real-time air temperature data to a server utilizing existing (or user deployed) Wi-Fi networks. This makes it ideally suited for deployment where wireless communications readily exist, notably urban areas. Assessment of the performance of the ASM relative to traceable standards in a water bath and atmospheric chamber show it to have good measurement accuracy with mean errors $< \pm 0.22^{\circ} \mathrm{C}$ between $-25^{\circ}$ and $30^{\circ} \mathrm{C}$, with a time constant in ambient air of $110 \pm 15 \mathrm{~s}$. Subsequent field tests also showed the ASM (in the custom shield) had excellent performance (RMSE $=0.13^{\circ} \mathrm{C}$ ) over a range of meteorological conditions relative to a traceable operational Met Office platinum resistance thermometer. These results indicate that the ASM and radiation shield are more than fit for purpose for dense network deployment in environmental monitoring applications at relatively low cost compared to existing observation techniques.
\end{abstract}

\section{Introduction}

Near-surface air temperature is of interest for a wide range of applications, such as frost protection in agriculture (Beckwith et al. 2004) or within urban areas, where the well-documented urban heat island (UHI) effect (e.g., Stewart and Oke 2012) has implications for the health and well-being of residents. However, there is a paucity of routine observations due to a multitude of factors, including the cost of instrumentation, security concerns, and siting requirements (Muller et al. 2013a). Thus, observations are often limited to one or two meteorological stations that may neither be collocated with nor truly representative of the surrounding environs in

Corresponding author address: Lee Chapman, School of Geography, Earth and Environmental Sciences, University of Birmingham, Edgbaston, Birmingham B15 2TT, United Kingdom.

E-mail: 1.chapman@bham.ac.uk respect to the application, and are certain not to capture smaller-scale variability, which may be of significant importance. With lower-cost meteorological sensors becoming available, of accuracy claimed to be comparable to existing instrumentation, there is scope to deploy highdensity networks of sensors to identify spatiotemporal patterns of meteorological variables across environments of interest, such as cities (Muller et al. 2013b) or vineyards (Matese et al. 2009). This potentially transformative approach would enable observation of the dynamic nature of temperature patterns in more detail than previously possible and could be used to aid real-time decision making (e.g., building energy usage, frost protection), data assimilation to improve and evaluate model performance (Chen et al. 2012), ground-truth remote sensing (Tomlinson et al. 2012), and verify crowd-sourced data quality (Overeem et al. 2013) at an unprecedented scale. However, confidence in the quality of measurements made by lower-cost sensors needs further investigation. 
This paper investigates the performance of a low-cost sensor with custom radiation shield (purchased together for approximately USD\$150): the Aginova Sentinel Micro (ASM, Aginova Inc., Mason, Ohio). Although this sensor was developed specifically for deployment within HiTemp (high-resolution temperature measurements within the urban environment) (Muller et al. 2013b), it is applicable to other situations that may benefit from a dense network (e.g., source area studies, atmospheric profiles) and those that require a rapid response to changing temperature conditions (e.g., ripening and frost detection for high-value crops in orchards and vineyards; Beckwith et al. 2004; Matese et al. 2009). An advantage of this sensor over existing low-cost air temperature sensors is inbuilt $\mathrm{Wi}-\mathrm{Fi}$ communications that allow transmission of data from sensor to server (either through existing wireless Internet infrastructure or via ad hoc networks formed of a computer and a wireless router), in near-real time.

\section{Wireless temperature sensor}

The ASM (Fig. 1) is a $10-\mathrm{k} \Omega$ negative temperature coefficient thermistor connected to a low-powered wireless communications card contained within a weatherproof enclosure (further specification given in Table 1). Power is provided by a single-cell AA 3.6-V lithiumthionyl chloride battery that is capable of providing the peak current $(150 \mathrm{~mA})$ required for radio transmission and, under good wireless network conditions, is reported to last up to 3 years (Aginova Inc. 2013).

Data communication uses standard Institute of Electrical and Electronics Engineers (IEEE) $802.11 \mathrm{~b} / \mathrm{g} 2.4-\mathrm{GHz}$ $\mathrm{Wi}-\mathrm{Fi}$ at bit rates of up to $11 \mathrm{Mbps}$. When located on existing Wi-Fi hotspots/networks, the sensor utilizes limited bandwidth (user datagram protocol packets $\approx 2 \mathrm{kB}$ ) and poses minimal risk to security, as sensor to Internet data packets are secured using the latest encryption and all communications are sensor initiated. Data packets are transmitted periodically (user definable) through the Internet (or local ad hoc network) to a server with Aginova WiBox software. The software manages sensor-to-server communication and enables sensor configuration and the viewing/downloading of data. Figure 2 provides an overview of communication pathways, sensor settings, and software.

The sensor has limited flash memory (1440 data points $=$ $24 \mathrm{~h}$ with 60 -s sampling); therefore, raw data are not stored on the sensor long term but are transmitted periodically to the server. To ensure continuity of data collection, data are kept until receipt confirmation is returned by the server. In locations with intermittent $\mathrm{Wi}$-Fi, further safeguards can be applied via a conditional

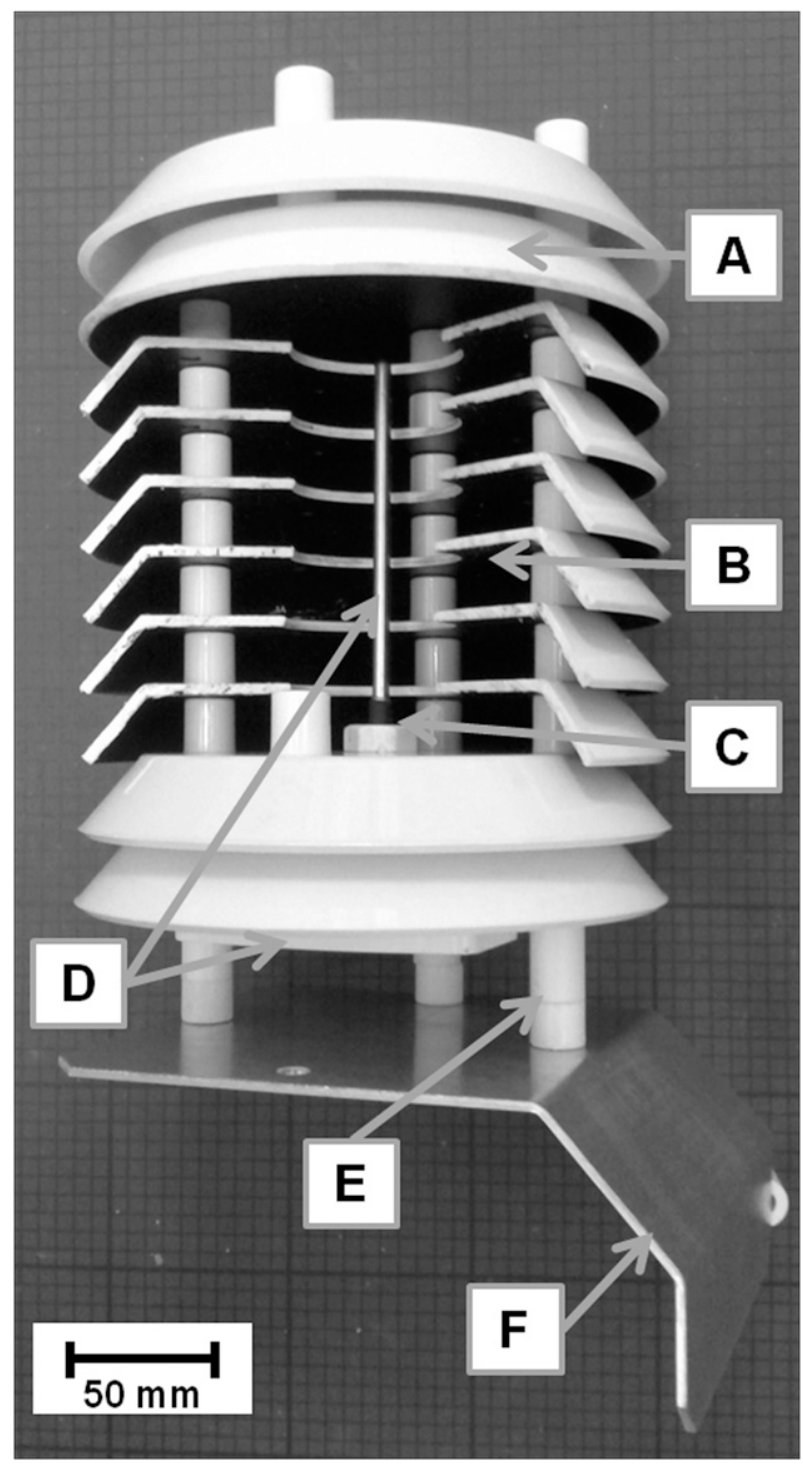

FIG. 1. Annotated photograph of the ASM sensor and radiation shield (with cut away section) developed with and parts provided by Aginova Inc.: A: additional shielding above sensing volume, B: black matte paint on underside of shield plates, C: nylon nut and bolt (M10) and probe sheathing (40 mm), D: ASM sensor housing and thermistor probe with 120-mm cable (different lengths available on request), E: plastic spacer $(45 \mathrm{~mm})$ to reduce antenna interference, and F: aluminum base plate (shield base: $110 \mathrm{~mm} \times$ $110 \mathrm{~mm}$; mounting face: $110 \mathrm{~mm} \times 30 \mathrm{~mm}$ ).

storage mode, so that data are only logged when there is a temperature change $\geq \pm 0.1^{\circ} \mathrm{C}$ between samples and server communication has been lost.

Thus, the self-contained ASM sensor requiring no additional power or communications, coupled with its lower-cost enables deployment of large numbers at a range of spatial scales, provided an accessible wireless network is available (e.g., Muller et al. 2013b). 
TABLE 1. Manufacturer specifications plus test results for three low-cost temperature sensors (Aginova Inc. 2013; Hubbart et al. 2005); Maxim Integrated (2014); Onset Computer Corporation (2014); Whiteman et al. 2000).

\begin{tabular}{|c|c|c|c|}
\hline \multirow[b]{2}{*}{ Characteristic } & \multicolumn{3}{|c|}{ Sensor specification } \\
\hline & ASM & Hobo Pro V2 logger & iButton \\
\hline Manufacturer & Aginova Inc. & Onset & Thermocron \\
\hline Part No. ${ }^{\mathrm{a}}$ & XPROBE-TEMP-0006 & U23-004 & DS1921G \\
\hline Dimensions (mm) & $65 \times 70 \times 20$ (width $\times$ length $\times$ height $)$ & $102 \times 38$ (length $\times$ diameter $)$ & $6 \times 17$ (height $\times$ diameter $)$ \\
\hline Weight $(\mathrm{g})$ & 84 & 118 & 3.3 \\
\hline Operating range $\left({ }^{\circ} \mathrm{C}\right)$ & -30 to +50 & -40 to +70 & -40 to +85 \\
\hline Reported accuracy $\left({ }^{\circ} \mathrm{C}\right)^{\mathrm{b}}$ & $< \pm 0.5(0$ to +40$)$ & $< \pm 0.21(0$ to +50$)$ & $< \pm 1.0(0$ to +40$)$ \\
\hline Tested accuracy $\left({ }^{\circ} \mathrm{C}\right)^{\mathrm{c}}$ & $< \pm 0.22(-25$ to +30$)$ & $< \pm 0.26(-5$ to +50$)$ & $< \pm 1.0(0$ to +24.9$)$ \\
\hline Resolution $\left({ }^{\circ} \mathrm{C}\right)$ & 0.1 & 0.02 & 0.5 \\
\hline Time constant $(\mathrm{s})^{\mathrm{d}}$ & $110 \pm 15$ & $122 \pm 6$ & Not tested \\
\hline Observation method & Thermistor probe & Thermistor probe & Digital sensor \\
\hline $\begin{array}{l}\text { Data storage } \\
\text { (No. of data points) }\end{array}$ & 1440 to $\sim 14000^{\mathrm{e}}$ & 42000 & 2048 \\
\hline Data collection & Wi-Fi 802.11 b/g & Manual collection & Manual collection \\
\hline Battery type & AA, 3.6-V, lithium-thionyl chloride & 1/2 AA, $3.6 \mathrm{~V}$, lithium & BR1225A, $3 \mathrm{~V}$, lithium \\
\hline Battery life (yr) & Up to 3 & Up to 3 & Up to 6 \\
\hline Radiation shield & Included-custom & RS3 (\$65)—custom & None \\
\hline $\operatorname{Cost}^{\mathrm{f}}$ & $\$ 150$ & $\$ 145$ & $\$ 23$ \\
\hline
\end{tabular}

${ }^{a}$ Latest version of sensor. Whiteman et al. (2000) and Nakamura and Mahrt (2005) used the HOBO H8 Pro. Hubbart et al. (2005) used the iButton DS1921L.

${ }^{\mathrm{b}}$ HOBO Pro V2 external temperature probe specification.

${ }^{\mathrm{c}}$ Tested accuracy in water undertaken by the authors, Whiteman et al. (2000), and Hubbart et al. (2005) for the ASM, Hobo H8 Pro, and iButton, respectively. Reported accuracy for Hobo $\mathrm{H} 8$ Pro was $< \pm 0.4^{\circ} \mathrm{C}$ over the range $0^{\circ}$ to $+40^{\circ} \mathrm{C}$.

${ }^{\mathrm{d}}$ Determined by the authors and Whiteman et al. (2000) for the ASM and HOBO H8 Pro, respectively.

${ }^{\mathrm{e}}$ ASM can log 1440 data points logged in normal mode and up to approximately 14000 in conditional storage mode. Long-term storage is not expected on the ASM, as data are transmitted back to the server at regular intervals.

${ }_{\mathrm{f}}^{\mathrm{f}}$ Approximate cost per single sensor (January 2014). Cost does not include additional cost for software and equipment required to collect data.

\section{Radiation shield}

An initial assessment of existing commercially available radiation shields revealed that many were more expensive than low-cost sensors, requiring a large capital outlay for network deployment. To address this, a custom nonaspirated radiation shield was designed for the ASM.
Following a review of the radiation shield literature (e.g., Anderson and Baumgartner 1998; Richardson et al. 1999; Nakamura and Mahrt 2005; Thomas and Smoot 2013) and a number of design iterations and field tests, a custom shield formed of $10 \mathrm{UV}$-resistant pressure-molded plastic plates was produced (Fig. 1). The design incorporates a fixing for the sensor housing and

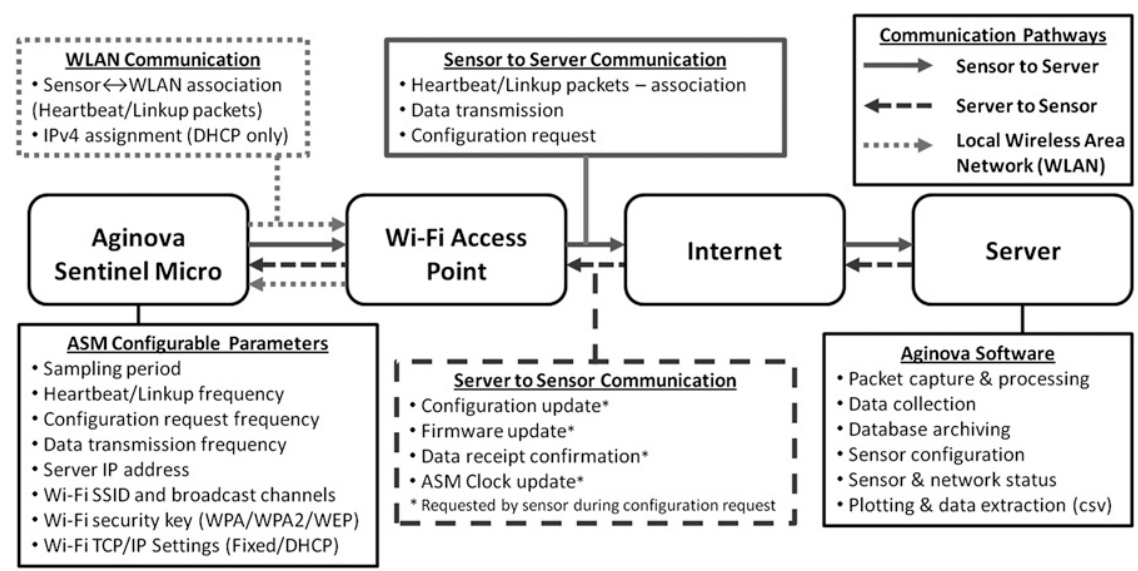

FIG. 2. Schematic of ASM communication pathways, user-definable settings, and server software features. 
a nylon bolt to hold the probe within the sensing volume; this coupled with additional rubber sheathing around the probe base minimizes conduction. Plastic spacers located above the base reduce signal interference to the antenna. The underside of the middle plates are painted matte black, which is now standard in Met Office (UKMO) plastic Stevenson screens (Perry et al. 2007), to reduce error due to reflected solar radiation. Testing of an unpainted design with a SKS1110 pyranometer (Skye Instruments, Llandrindod Wells, United Kingdom) mounted within the radiation shield (after Hubbard et al. 2001) found between $50 \%$ and $75 \%$ of reflected solar radiation in the sensing volume. After application of the paint, this was reduced to $<5 \%$. The shield plates are held together by four metal threaded bars screwed into the top plate and secured to the base plate, which can be customized to meet site mounting requirements (51-mm stainless steel U-bolts used in field testing).

\section{Methods}

\section{a. Time constant}

The time constant, the time taken to reach $63.2 \%$ of a prescribed step change (e.g., Whiteman et al. 2000), for operational air temperature sensors is required to be $<20$ s to meet World Meteorological Organization (WMO) specifications (WMO 2008). Typically low-cost temperature sensors do not meet this requirement due to their construction. This deficiency can be overcome by selecting an appropriate sampling rate that is representative of the process observed ( 1 and $60 \mathrm{~s}$ for laboratory and field, respectively, in this study) before being averaged over a longer (15 min) period (Kurzeja 2010).

The time constant of five randomly selected ASMs were measured in a naturally ventilated laboratory following a step change of $-10^{\circ}$ to $25^{\circ} \mathrm{C}$, generated by removal from a freezer into a warm room (after Whiteman et al. 2000). The ASMs were tied together, so the tips of the probes were reasonably close to each other but not touching. The process was repeated three times with a sensor sampling rate of $1 \mathrm{~Hz}$.

\section{b. Accuracy}

The accuracy of four ASMs was tested over a temperature range of $-25^{\circ}$ to $40^{\circ} \mathrm{C}$ as part of an academic collaboration with the UKMO in their Instrumentation Laboratory. Two sensors were placed in a Vötsch Industrietechnik VT4011 atmospheric chamber (Balingen, Germany) and compared against a Thermocoax Air Platinum Resistance Thermometer (Flers, France); the other two sensors were submerged in a PSL Scientific System 1 water bath (Clausthal-Zellerfeld, Germany) and compared with a Tinsley SPRT "C" (serial number
238701; Redhill, United Kingdom) connected to an A $\Sigma$ A Automatic Systems Laboratories resistance bridge (model F17A; Redhill, United Kingdom). Both systems have a certified National Physical Laboratory (NPL) calibration uncertainty of $\pm 0.1^{\circ} \mathrm{C}$ (calibrated 2012).

\section{c. Field tests}

Three ASMs were deployed (60-s sampling) within the custom radiation shield over eight test periods (of varying lengths) between January and July 2013, at the UKMO Winterbourne No. 2 meteorological observation site $\left(52.456^{\circ} \mathrm{N},-1.927^{\circ} \mathrm{W}\right.$; elevation $140 \mathrm{~m}$; metadata at http://www.bucl.bham.ac.uk/data/WinterbourneNo2 metadata.pdf; Muller et al. 2013c). Sensors were mounted onto a test bed frame at a height of $1.25 \mathrm{~m}$ over grass (no snow occurred during the tests), between 2 and $3 \mathrm{~m}$ to the west of the station Stevenson screen that housed the UKMO platinum resistance thermometer (PRT) (1-min average data). The screen PRT was selected as the reference due to its operational usage, traceability against national standards due to annual calibration, and the absence of an aspirated radiation shield at the site.

Additional observations for analysis of shield performance included incoming shortwave solar radiation using a Kipp \& Zonen CMP 3 (Delft, Netherlands) and wind speed $(1.25 \mathrm{~m})$ using a Gill WindSonic (Lymington, United Kingdom) sampling at $1 \mathrm{~Hz}$.

\section{d. Data analysis techniques}

For analysis, raw 60-s air temperature data from each ASM were corrected based on temperature offsets determined from the accuracy tests (section 4b) before being averaged over 15-min periods to account for differences in sensor and PRT time constants and sampling frequency (Kurzeja 2010).

Exploratory autocorrelation analyses of the 15-min ASM and PRT (Met Office 2013) mean data highlighted statistically significant serial dependence. To assess goodness of fit between each sensor and the PRT, generalized additive models (GAMs) were used, as they are suitable for serially autocorrelated data. GAMs, which use nonparametric functions to maximize the quality of fit to the data (Hastie and Tibshirani 1990; Wood 2004), were fit using the mixed GAM computation vehicle (mgcv) package in R (Wood 2013). The PRT observations were used as the independent variable.

\section{Results}

\section{a. Time constant}

The time constant, calculated from the 15 samples, of the time taken for sensors to reach $12.1^{\circ} \mathrm{C}(63.2 \%$ of 


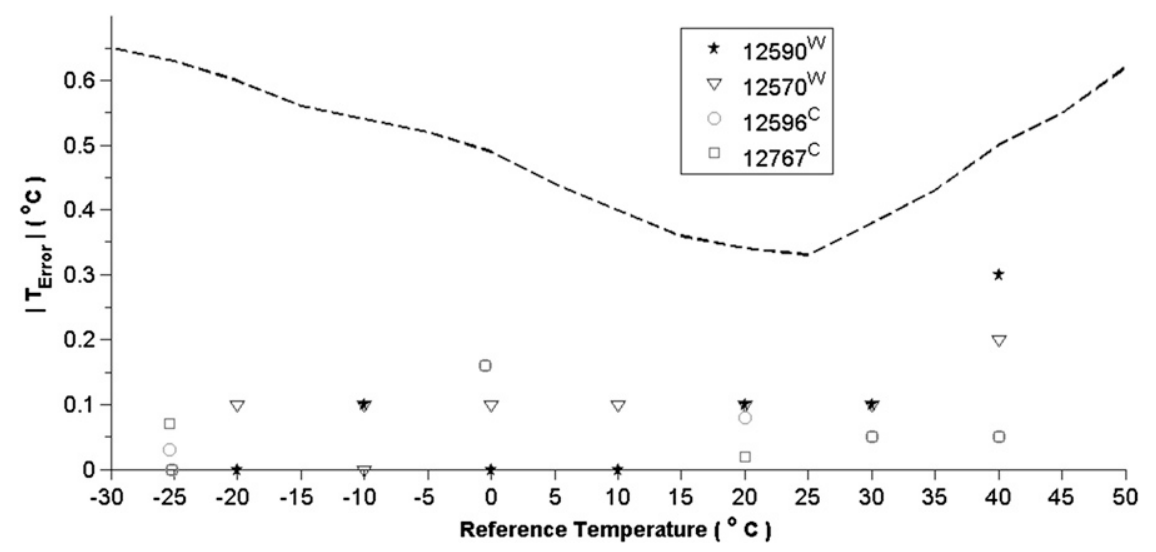

FIG. 3. Observed temperature errors of four ASM probes (serial numbers given in key) relative to a reference temperature (UKMO PRT, traceable to national standards) of a water bath (superscript W) and atmospheric chamber (superscript $\mathrm{C}$ ) during experiments undertaken within the UKMO Instrumentation Laboratory. Dashed line represents the probe accuracy as reported by Aginova.

$-10^{\circ}$ to $25^{\circ} \mathrm{C}$ step change) in ambient air was $110 \mathrm{~s}$ with a standard deviation of $\pm 15 \mathrm{~s}$. Although this time constant is slower than that recommended (WMO 2008) for operational instrumentation (sampling rates $<60$ s), it is of similar magnitude to other low-cost thermistor probes currently available (e.g., HOBO H8 Pro; Table 1; Whiteman et al. 2000).

\section{b. Sensor accuracy}

Tests undertaken at the UKMO Instrumentation Laboratory indicated that all four sensors observed temperatures were within $\pm 0.22^{\circ} \mathrm{C}$ (over the range $-25^{\circ}$ to $30^{\circ} \mathrm{C}$ ) of that of the water bath and chamber (Fig. 3). This is smaller than the error ranges obtained by Aginova (Table 1) in their laboratory sensor resistance testing (K. Baumgartner 2011, personal communication). When the sensors were within the water bath, they were within $\pm 0.1^{\circ} \mathrm{C}$ across the same temperature range. At $40^{\circ} \mathrm{C}$ the difference was found to be slightly greater $\left( \pm 0.27^{\circ} \mathrm{C}\right)$ in both media, in part due to the nonlinear relation between resistance and temperature of thermistor probes (McGee 1988).

\section{c. Field tests}

The general field performance of three ASMs was assessed using 15-min averaged data from the UKMO Winterbourne No. 2 meteorological observation site. A GAM was fit to data from 6006 periods, during which screen temperatures were between $-3.9^{\circ}$ and $29.3^{\circ} \mathrm{C}$. Temperature errors $\left(T_{\mathrm{Error}}=T_{\mathrm{ASM}}-T_{\mathrm{GAM}}\right)$ ranged from $-0.76^{\circ}$ to $2.56^{\circ} \mathrm{C}$, with the largest errors typically occurring around sunrise, although such errors were not seen consistently (Fig. 4). This could be a result of low sun angles increasing radiation error (Anderson and Baumgartner 1998) or more probably when there is limited mixing, resulting in poor ventilation through the shield because conditions are stable with low friction velocity (Richardson et al. 1999; Harrison 2010). As the larger errors $\left[T_{\text {Error }}> \pm 3 \times\right.$ interquartile range (IQR); $2.0 \%$ of data] occurred at low wind speeds $\left(<1 \mathrm{~m} \mathrm{~s}^{-1}\right.$; Fig. 4), poor ventilation is the most likely reason. However, PRT observation errors are likely large at these times, as it is housed in an unventilated screen (Harrison 2010). Despite these few large errors, the root-meansquare error (RMSE) for the whole period was $0.13^{\circ} \mathrm{C}$. This is marginally larger than the measurement uncertainty of the PRT.

Analysis of day (1000-1500 UTC, 1214 periods) and night (2200-0400 UTC, 1534 periods) $T_{\text {Error }}$ showed RMSEs of $0.10^{\circ}$ and $0.11^{\circ} \mathrm{C}$, respectively. It is encouraging that $95 \%$ of temperature errors had a magnitude of $<0.27^{\circ} \mathrm{C}$ during night periods when wind was $<1.0 \mathrm{~m} \mathrm{~s}^{-1}$, with no errors exceeding $0.61^{\circ} \mathrm{C}$. The application of a black coating on the underside of the radiation shield appears justified, as temperature error magnitude did not exceed $0.42^{\circ} \mathrm{C}$ during the day hours when solar irradiance was at its maximum (observed range: $8.5-1031 \mathrm{~W} \mathrm{~m}^{-2}$ ), even at wind speeds $<1 \mathrm{~m} \mathrm{~s}^{-1}$, where the magnitude of $95 \%$ of errors did not exceed $0.22^{\circ} \mathrm{C}$.

The overall performance of the custom radiation shield is particularly promising due to the magnitude of temperature errors ( $95 \%$ of data) being $< \pm 0.24^{\circ} \mathrm{C}$ for all conditions (Fig. 4). The daytime RMSE $\left(0.10^{\circ} \mathrm{C}\right)$ exceeds the performance of other field tests of low-cost sensors in unaspirated shields (e.g., Whiteman et al. 2000: $0.2^{\circ} \mathrm{C}$; Nakamura and Mahrt 2005: $0.39^{\circ} \mathrm{C}$ ) albeit under differing 


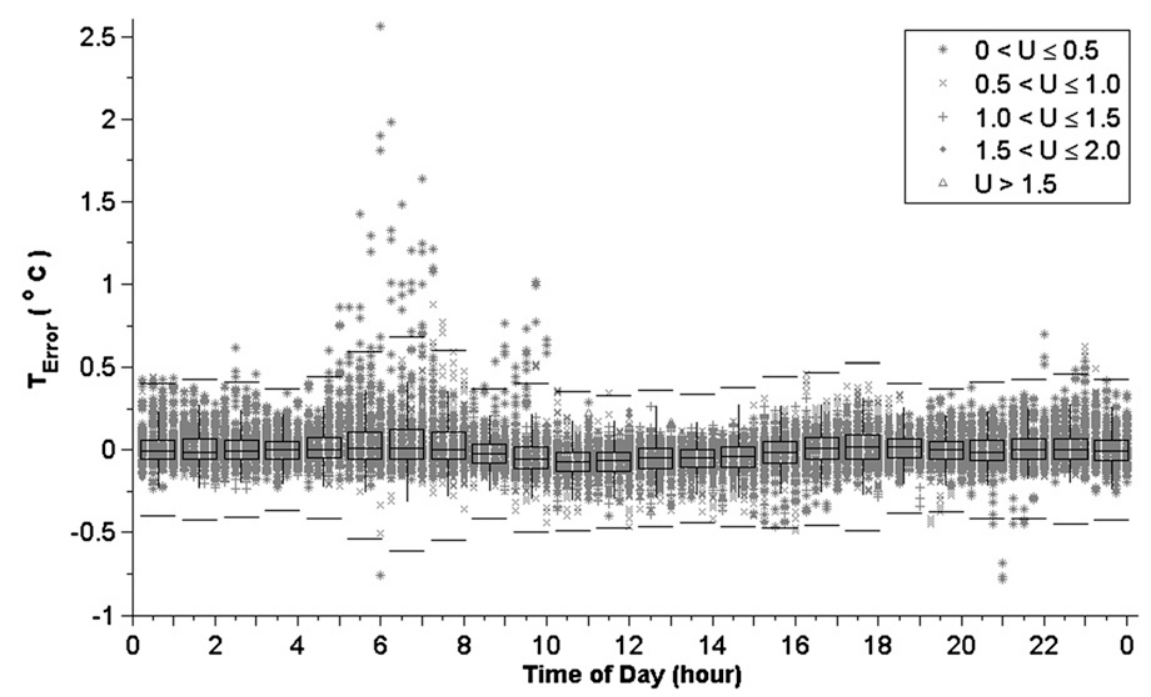

FIG. 4. Temperature errors $\left({ }^{\circ} \mathrm{C}\right)$ determined using a GAM analysis of 15 -min average air temperature from three ASM sensors (serial numbers 12681,12682, and 12672), in custom radiation shields, relative to screen UKMO PRT temperature during field trials conducted over eight periods (of varying lengths) between January and July 2013. The hourly IQR (25th and 75 th percentile) boxplots have \pm 1.5 IQR whiskers plus horizontal lines at \pm 3.0 IQR. Points above/below these points are considered outliers. The 15-min average sonic anemometer wind speed $\left(\mathrm{U}, \mathrm{m} \mathrm{s}^{-1}\right)$ observed at $1.25 \mathrm{~m}$ for each $T_{\text {Error }}$ is represented by the symbols given in the figure legend.

meteorological conditions. Further reduction in measurement uncertainty may be achieved by determining a radiation correction for the shield using a combination of modeling and observation (e.g., Nakamura and Mahrt 2005; Mauder et al. 2008) and increasing ventilation of the sensing volume (Harrison 2010).

\section{Conclusions}

Testing of the low-cost ASM sensor shows it to perform very well relative to national standards in the laboratory [accuracy $< \pm 0.22^{\circ} \mathrm{C}\left(-25^{\circ}\right.$ to $\left.30^{\circ} \mathrm{C}\right)$ ] and traditional traceable operational observing techniques (PRT) in the field (daytime RMSE $=0.10^{\circ} \mathrm{C}$ ), as well as relative to existing lower-cost sensors on the market (Table 1 ). This performance coupled with Wi-Fi connectivity enables sensors to collect and provide raw sampled data in near-real time to end users. This has the potential benefit of allowing deployment in large numbers of locations that may include those where current operational observation methods are impractical, coupled with being able to provide the data rapidly to a wide range of end users who are eager to have data in such places for decision making and real-time operations (Grimmond 2013).

The custom shield shows promising performance in initial field tests with very few large temperature errors relative to the screen PRT during periods of high solar insolation even when wind speeds were low $\left(<1 \mathrm{~m} \mathrm{~s}^{-1}\right)$. During periods of low wind speed despite errors being slightly larger, the majority (95\%) of observations were within $\pm 0.24^{\circ} \mathrm{C}$ of an UKMO PRT.

Ongoing work is underway to test sensor-shield performance over a wider range of meteorological conditions, to determine if sensor calibration drift is a problem after extended deployment in the field, and to gain a better understanding of the radiation error (both longwave and shortwave) within the sensing volume, so that an appropriate correction factor could be determined. Notwithstanding these ongoing tests, it is concluded that the low-cost ASM sensor and radiation shield are more than fit for purpose for network deployment in environmental monitoring applications.

Acknowledgments. This work is funded by the U.K. Natural Environment Research Council (NERC)'s "Network of Sensors" project HiTemp (Grants NE/ I006915/1 and NE/I007032/1; further information at www. bucl.org.uk). The authors thank Mike Molyneux and Paula Taylor for use of UKMO's testing laboratory; Aginova Inc. for their collaboration in the development of the sensor and radiation shield; and from the University of Birmingham, Elliott Warren, Grace Garner, Sophie Bland, and Richard Johnson. 


\section{REFERENCES}

Aginova Inc., cited 2013: Sentinel Micro with probe: Wi-Fi temperature sensor. [Available online at http://www.aginova.com/ wifi_sensor_sentinel_micro_with_probe.php.]

Anderson, S. P., and M. F. Baumgartner, 1998: Radiative heating errors in naturally ventilated air temperature measurements made from buoys. J. Atmos. Oceanic Technol., 15, 157-173, doi:10.1175/1520-0426(1998)015<0157:RHEINV>2.0.CO;2.

Beckwith, R., D. Teibel, and P. Bowen, 2004: Report from the field: Results from an agricultural wireless sensor network. Proceedings of the 29th Conference on Local Computer Networks, IEEE, 471-478, doi:10.1109/LCN.2004.105.

Chen, F., and Coauthors, 2012: Research priorities in observing and modeling urban weather and climate. Bull. Amer. Meteor. Soc., 93, 1725-1728, 10.1175/BA MS-D-11-00217.1.

Grimmond, C. S. B., 2013: Observing London: Weather data needed for London to thrive. London Climate Change Partnership, $81 \mathrm{pp}$. [Available online at http://climatelondon. org.uk/wp-content/uploads/2013/07/Observing-London-Final. pdf.]

Harrison, R. G., 2010: Natural ventilation effects on temperatures within Stevenson screens. Quart. J. Roy. Meteor. Soc., 136, 253-259, doi:10.1002/qj.537.

Hastie, T., and R. Tibshirani, 1990: Exploring the nature of covariate effects in the proportional hazards model. Biometrics, 46, 1005-1016, doi:10.2307/2532444.

Hubbard, K. G., X. Lin, and E. A. Walter-Shea, 2001: The effectiveness of the ASOS, MMTS, Gill, and CRS air temperature radiation shields. J. Atmos. Oceanic Technol., 18, 851-864, doi:10.1175/1520-0426(2001)018<0851:TEOTAM >2.0.CO;2.

Hubbart, J., T. Link, C. Campbell, and D. Cobos, 2005: Evaluation of a low-cost temperature measurement system for environmental applications. Hydrol. Processes, 19, 1517-1523, doi:10.1002/hyp.5861.

Kurzeja, R., 2010: Accurate temperature measurement in a naturallyaspirated radiation shield. Bound.-Layer Meteor., 134, 181-193, doi:10.1007/s10546-009-9430-2.

Matese, A., S. F. Di Gennaro, A. Zaldei, L. Genesio, and F. P. Vaccari, 2009: A wireless sensor network for precision viticulture: The NAV system. Comput. Electron. Agric., 69, 51-58, doi:10.1016/j.compag.2009.06.016.

Mauder, M., R. L. Desjardins, Z. Gao, and R. van Haarlem, 2008: Errors of naturally ventilated air temperature measurements in a spatial observation network. J. Atmos. Oceanic Technol., 25, 2145-2151, doi:10.1175/2008JTECHA1046.1.

Maxim Integrated, cited 2014: DS1921G: Thermochron iButton device. [Available online at http://www.maximintegrated. com/datasheet/index.mvp/id/4023.]

McGee, T. D., 1988: Principles and Methods of Temperature measurement. John Wiley \& Sons, $581 \mathrm{pp}$.

Met Office, cited 2013: Met Office Integrated Data Archive System (MIDAS) land and marine surface stations data (1853-current). NCAS British Atmospheric Data Centre. [Available online at http://badc.nerc.ac.uk/view/badc.nerc.ac.uk__ATOM__ dataent_ukmo-midas.]
Muller, C. L., L. Chapman, C. S. B. Grimmond, D. T. Young, and X.-M. Cai, 2013a: Sensors and the city: A review of urban meteorological networks. Int. J. Climatol., 33, 1585-1600, doi:10.1002/joc.3678.

,,,,---- and,$- 2013 \mathrm{~b}$ : Birmingham urban climate laboratory (BUCL): Experiences, challenges and applications of an urban temperature network. Geophys. Res. Abstr., 15, 3325.

$-, \ldots,-, \ldots$, and ——, 2013c: Toward a standardized metadata protocol for urban meteorological networks. Bull. Amer. Meteor. Soc., 94, 1161-1185, doi:10.1175/ BAMS-D-12-00096.1.

Nakamura, R., and L. Mahrt, 2005: Air temperature measurement errors in naturally ventilated radiation shields. J. Atmos. Oceanic Technol., 22, 1046-1058, doi:10.1175/JTECH1762.1.

Onset Computer Corporation, cited 2014: HOBO U23 Pro V2 external temperature data logger-U23-004. [Available online at http://www.onsetcomp.com/products/data-loggers/u23-004.]

Overeem, A., J. C. R. Robinson, H. Leijnse, G. J. Steeneveld, B. K. P. Horn, and R. Uijlenhoet, 2013: Crowdsourcing urban air temperatures from smartphone battery temperatures. Geophys. Res. Lett., 40, 4081-4085, doi:10.1002/grl.50786.

Perry, M. C., M. J. Prior, and D. E. Parker, 2007: An assessment of the suitability of a plastic thermometer screen for climatic data collection. Int. J. Climatol., 27, 267-276, doi:10.1002/ joc. 1381 .

Richardson, S. J., F. V. Brock, S. R. Semmer, and C. Jirak, 1999: Minimizing errors associated with multiplate radiation shields. J. Atmos. Oceanic Technol., 16, 1862-1872, doi:10.1175/ 1520-0426(1999)016<1862:MEAWMR > 2.0.CO;2.

Stewart, I. D., and T. R. Oke, 2012: Local climate zones for urban temperature studies. Bull. Amer. Meteor. Soc., 93, 1879-1900, doi:10.1175/BAMS-D-11-00019.1.

Thomas, C. K., and A. R. Smoot, 2013: An effective, economic, aspirated radiation shield for air temperature observations and its spatial gradients. J. Atmos. Oceanic Technol., 30, 526537, doi:10.1175/JTECH-D-12-00044.1.

Tomlinson, C. J., L. Chapman, T. E. Thornes, and C. J. Baker, 2012: Derivation of Birmingham's summer surface urban heat island from MODIS satellite images. Int. J. Climatol., 32, 214-224, doi:10.1002/joc.2261.

Whiteman, C. D., J. M. Hubbe, and W. J. Shaw, 2000: Evaluation of an inexpensive temperature datalogger for meteorological applications. J. Atmos. Oceanic Technol., 17, 77-81, doi:10.1175/ 1520-0426(2000)017<0077:EOAITD>2.0.CO;2.

Wood, S. N., 2004: Stable and efficient multiple smoothing parameter estimation for generalized additive models. J. Amer. Stat. Assoc., 99, 673-686, doi:10.1198/016214504000000980.

_ 2013: Mixed GAM computation vehicle with GCV/AIC/ REML smoothness estimation. Comprehensive R Archive Network, 219 pp. [Available from http://cran.at.r-project.org/ web/packages/mgcv/mgcv.pdf.]

World Meteorological Organization, 2008: Guide to meteorological instruments and methods of observation. 7th ed. WMO Rep. WMO-8, 681 pp. 